\title{
PENGOLAHAN LIMBAH CAIR DISPENSING PADA PROSES FASET MENGGUNAKAN MULTIMEDIA FILTER DI OPTIK AHUR KOTA CIMAHI TAHUN 2020
}

\author{
Hotman P. Simajuntak ${ }^{1)}$, Ono Taryono ${ }^{2)}$, Mega Sofiana ${ }^{3)}$ \\ ${ }^{1,3)}$ Program Stui Diploma Tiga Opthometri STIKes Dharma Husada \\ 2) Politeknik STIA LAN BAndung \\ 1)Omanvw@gmail.com \\ ${ }^{2)}$ simalem@yahoo.com \\ 3)egga.annyta@gmail.com
}

\begin{abstract}
Abstrak
Mentri Perindustrian mengatakan bahwa dengan kebutuhan masyarakat yang meningkat, terkait penggunaan kacamata, maka produksi pembuatan kacamata pun akan meningkat yang di sesuaikan dengan kebutuhan masyarakat. Dalam-proses nya pembuatan kacamata akan menghasilkan limbah. Yang selanjutnya lingah ini akan di teliti yang memiliki tujuan untuk mengetahui pengolahan limbah cair dispensing pada proses faset. Penelitian ini adalah jenis penelitian experimental dengan menggunakan metode one shot case study. Dan didapatkan hasil dari penelitian menggunakan multimedia filter ini telah memenuhi standar baku mutu air limbah menurut Peraturan Menteri Lingkungan Hidup Republik Indonesia Nomor 5 Tahun 2014 Tentang Baku Mutu Air Limbah bagi usaha atau kegiatan fasilitas pelayanan kesehatan. Dengan hasil output yang dihasilkan oleh multimedia filter pada percobaan ke 3 adalah sebesar $\mathrm{pH} 7.1$ - 7.0. Sehingga telah tercapainya peningkatan baku mutu limbah dan baku mutu air. Dan dapat dijadikan bahan pertimbangan bagi pengusaha Optik sebagai pelayanan kesehatan untuk dapat memperhatikan personal hygiene bagi Opthometris yang ada di optik dan sanitasi lingkungan, serta bahan pertimbangan bagi Dinas Lingkungan hidup agar industri Optik dapat mengolah limbah cair dan memanfaatkannya dengan baik.
\end{abstract}

Kata Kunci : Dispensing, Limbah faset, Multimedia Filter

\section{PENDAHULUAN}

Perkembangan teknologi ke arah serba digital saat ini semakin pesat, diikutu gaya hidup baru yang tidak bisa dilepaskan dari perangkat yang serba elektronik. Saat ini masyarakat Indonesia lebih sering melakukan aktifitasnya menggunakan perangkat digital seperti gadget, komputer, televisi dan laptop.

Kebiasaan tersebut mengakibatkan kemampuan mata untuk berakomodasi akan lebih kuat. Dampak yang terjadi pada seseorang yang matanya normal akan memiliki kelainan refraksi atau yang telah memiliki kelainan refraksi akan memperparah keadaan seiring berjalannya waktu dan usia. Dari pengaruh tersebut diperlukan kacamata untuk melindungi matanya dari kelainan refraksi.

Kelainan refraksi mata adalah suatu keadaan dimana bayangan tidak dibentuk tepat di retina, melainkan di bagian depan atau belakang bintik kuning dan tidak terletak pada satu titik yang tajam. Kelainan refraksi dikenal dalam beberapa bentuk, yaitu: miopia, hipermetropia, dan astigmatisma (Ilyas, 2013).

Semakin meningkat angka kejadian kelainan refraksi, meningkat pul permintaan dan 
penggunaan kacamata sebagai antisipasi mengurangi kelainan refraksi. Hal tersebut mengakibatkan semakin banyak optik sebagai salah satu bisnis penyedia kacamata yang dibutuhkan oleh sebagian masyarakat yang memiliki kelainan refraksi atau yang hanya membutuhkan perlindungan mata melalui penggunaan kacamata, seperti penggunaan lensa anti UV. (Wawan Setiawan, 2017)

Perkembangan industri optik pembuatan kacamata saat ini sangat pesat. Hal ini akan menghasilkan limbah yang banyak. Salah satu kegiatan pembuatan kaca mata yang menghasilkan limbah adalah pada kegiatan faset. Limbah kegiatan faset berupa limbah padat dan cair dan tergolong dalam limbah B3 (bahan, beracun, berbahaya). Jika limbah dari kegiatan faset tersebut tidak dikelola dengan baik, sangat mungkin akan berdampak buruk bagi lingkungan dan kesehatan Opthometris yang melakukan kegiatan faset.

Kondisi lapangan yang ditemui saat ini, masih banyak optik yang belum melakukan pengelolaan limbah dengan baik dan membuang cairan limbah ke perairan. Berdasarkan hal tersebut,, peneliti tertarik untuk meneliti bagaimana cara pengolahan limbah cair dispensing pada proses faset menggunakan Multimedia Filter. Dalam penelitian ini akan dijelaskan bagaimana instalasi pengolahan limbah cair dispensing pada proses faset. Air limbah hasil kegiatan faset akan diolah sehingga menghasilkan limbah cair dengan karakteristik yang sesuai dengan stnadar baku mutu yang ditetapkan untuk dapat dibuang ke perairan tanpa merusak lingkungan dan kesehatan.

\section{METODE}

Metode penelitian adalah metode experimental di satu populasi, yaitu Optik Ahur, Penelitian dilakukan dengan cara memberikan treatment atau perlakuan tertentu terhadap subjek penelitian. Sampel yang digunakan merupakan sampel jenuh (saturation sampling) berupa limbah cair dispensing (sebagai media yang akan diteliti) dan data lembar observasi (sebagai lembar penilaian). Pengumpulan data pada penelitian ini adalah dengan menggunakan instrumen lembar observasi dan alat ukur $\mathrm{pH}$ meter sebagai metode penunjang penelitian

Penelitian dilakukan pada bulan Februari sampai dengan Mei 2020 di Optik Ahur Kota Cimahi. .Dalam pelaksanaan penelitian, peneliti dibantu 2 orang yaitu tenaga ahli kimia di salah satu perusahaan textil yang sudah memiliki pengalaman dibidangnya selama 10 tahun dan seorang yang bekerja di bidang pengolahan limbah WTM (water treatment) yang sudah bekerja selama 7 tahun. Instrument penelitian yang digunakan adalah lembar observasi dan $\mathrm{pH}$ meter

\section{Tahapan penelitian}

\section{a. Tahapan Pembuatan Design}

Design multimedia filter berupa pengolahan limbah cair secara fisika dan kimia yang telah dimodifikasi. Tahapan awal pembuatan design adalah : 
- Menentukan tata letak penggunaan alat dari mulai mesin faset, bak penampung, hingga multimedia filter

- Membuat sketsa secara kasar dengan menggunakan softwear paint.

\section{Bahan dan Alat}

\begin{tabular}{|l|l|l|}
\hline No. & \multicolumn{1}{|c|}{ Bahan } & \multicolumn{1}{c|}{ Gambar } \\
\hline 1 & $\begin{array}{l}\text { Akrilik penyekat } \\
\text { wadah }\end{array}$ & \\
\hline 2 & $\begin{array}{l}\text { Box sebagai } \\
\text { media wadah }\end{array}$ & \\
\hline 3 & $\begin{array}{l}\text { wadah sebagai } \\
\text { bak penampung }\end{array}$ \\
\hline 5 & Foam filter & \\
\hline 5 & \\
\hline
\end{tabular}

\section{b. Tahapan Pembuatan Media}

Pada dasarnya komponen yang menjadi bahan baku pembuatan multimedia filter adalah bahan baku dan alat pembuatannya

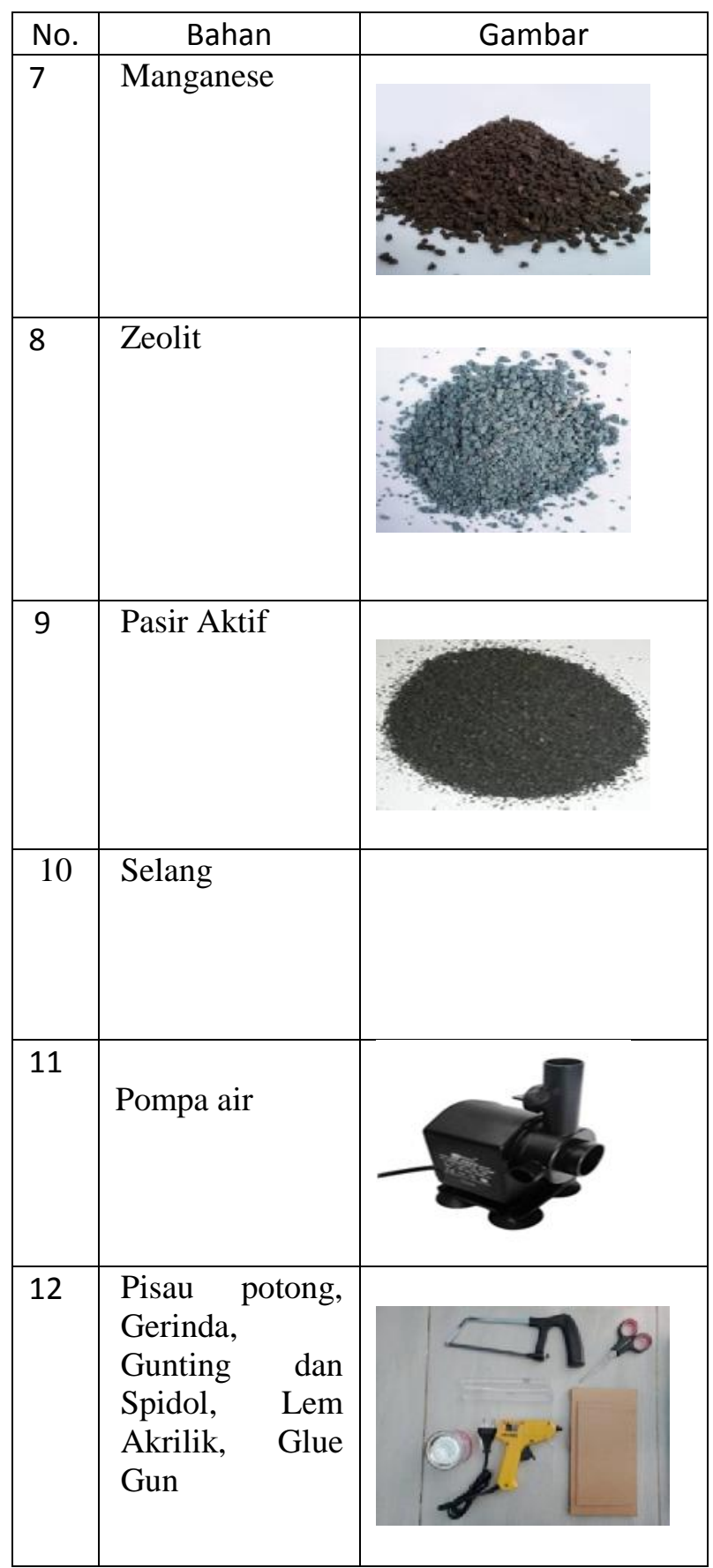




\section{Cara Pembuatan :}

- Membuat sketsa multimedia filter

- Memotong case filter dari akrilik dengan 6 sekat, menggunakan mesin potong, dan melubangi box wadah menggunakan pisau, disesuaikan dengan ukuran selang sebagai jalur keluar masuknya air limbah.

- Beri celah di setiap sekat di bagian atas dan bawah
- Memasukan media ke dalam case filter (satu media per bagian).

- Siapkan pompa untuk mendorong air dari bak penampungan 1 ke bak penampung 2, dan dari bak penampungan 2 ke bak penampungan 3 .

Buat instalasi keluar dari lubang keluar filter ke penampungan hasil air bersih

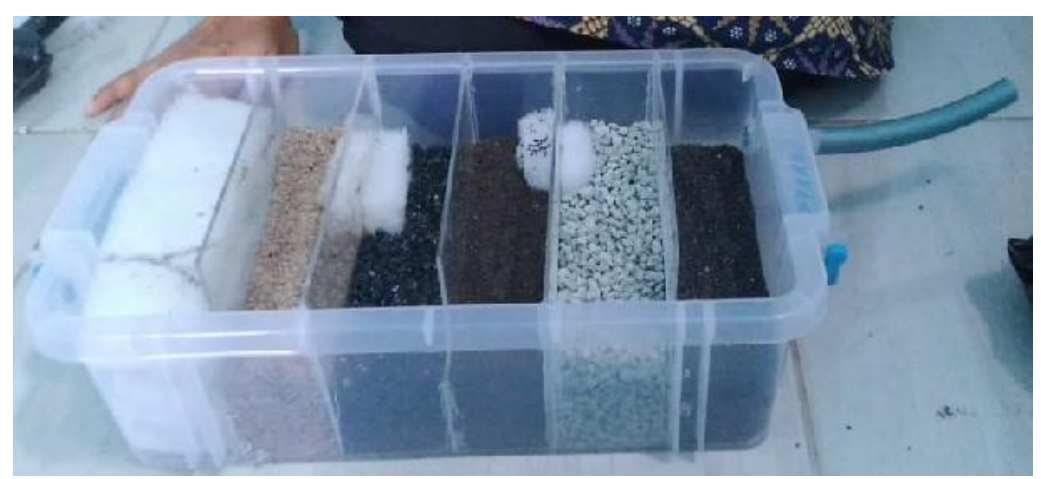

Gambar 1 Multimedia Filter

c. Pelaksanaan Penelitian

kegiatan faset Optik Ahur menggunakan air bersih dengan $\mathrm{pH} 7.1$ dan menghasilkan limbah cair dispensing kurang lebih sebanyak 5 Liter air limbah perhari, dengan $\mathrm{pH}$ air 8.3 (bersifat basa).

Proses pengolahan air limbah dilakukaan dengan menggunakan cara fisika dengan tahapan awal sebagai berikut :

1) Bak pengumpul

Air limbah proses dispensing faset dialirkan kedalam bak penampung 1 menggunakan pipa aliran yang terbuat dari selang ke bak penampung 2. Bak penampung ini berfungsi untuk menampung hasil limbah dispensing cair yang kemudian dialirkan kembali ke bak penampungan ke 3 untuk selanjutnya diberikan penambahan bahan koagulan dan di alirkan ke multimedia filter, yang posisinya terletak lebih tinggi dibandingkan bak penampung 1 .

2) Pompa Air

Dari bak penampung 1 limbah dialirkan ke bak penampung 2 menggunakan tenaga dari pompa air otomatis sehingga proses filtrasi memiliki regulasi yang lancar dan agar air limbah memiliki tekanan yang kuat menuju 
bak penampung 2, lalu dari bak penampungan 2 limbah dialirkan kembali ke bak penampungan 3 menggunakan pompa air, dan dari nak penampungan ke 3 menuju multimedia filter tidak menggunakan pompa air agar tekanan ke multimedia filter tidak terlalu kencang.

3) Multimedia Filter

Filter ini merupakan rangkaian penyaringan dengan enam jenis bahan penyaringan, yaitu pasir silika, karbon aktif, manganese, zeolit, yang masing masing dari bagian tersebut ditambahkan foam filter. Proses ini akan mengurangi polutan dari limbah cair yang akan di alirkan ke bak air bersih. Berikut penjelasan penggunaan multimedia flter.

- Part 1

Pada bagian ke - 1 ini terdapat foam filter yang berfungsi menyaring partiker halus yang mengendap pada limbah cair dispensing agar pada tahapan penyaringan di part selanjutnya komponen padat dapat berkurang dan polutan dalam air limbah dapat berkurang.

- Part 2

Di bagian ke - 2 multimedia filter terdapat pasir silika yang disisipkan foam filter untuk memaksimalkan penyaringan. Pada part 2 ini yang sangat berperan aktif adalah pasir silika yang fungsinya digunakan untuk menyaring lumpur atau limbah berpartikel besar ataupun kecil dalam air dan biasa digunakan untuk penyaringan tahap awal.

- Part 3

Di bagian ke - 3 terdapat karbon aktif yang di sisipkan foam filter untuk memaksimalkan penyaringan. karbon aktif berperan untuk menyerap bau, menjernihkan air, menghilangkan klorin (bahan pemutih), menghilangkan berbagai kontaminasi air. Dengan banyaknya jumlah pori-pori yang dimiliki, maka carbon active ini dapat dengan mudah menyerap berbagai endapan yang ada pada air tersebut.

- Part 4

Di bagian ke - 4 ini tersapat pasir manganese yang disisipkan foam filter untuk memaksimalkan penyaringan. manganese berperan untuk mengurangi kadar zat besi, zat mangan dan Hidrogen Sulfida atau H2S dalam air. Sehingga, pasir mangan memang cocok untuk digunakan dalam mengatasi beberapa masalah air sumur seperti air bau karat, air berlapis minyak, air yang mengakibatkan endapan kuning dan hitam di dasar wadah penampungan air, dan air yang berbau.

\section{- Part 5}

Di bagian ke -5 ini terdapat zeolit yang disisipkan foam filter dan memiliki fungsi yang penting dalam filtrasi, yaitu zeolit dapat memisahkan molekul 
berdasarkan ukuran, bentuk, polaritas dari molekul yang disaring. Penggunaan zeolit sebagai penyaring didasari oleh volume dan ukuran garis tengah ruang kosong dalam kisi-kisi kristal zeolit. Banyaknya jumlah ruang kosong pada kristal zeolit berbanding lurus dengan besarnya daya saring zeolit.

Zeolit adalah produk tambang berfungsi untuk meningkatkan kadar oksigen, memberikan segar dalam air dan menyerap zat kapur ringan dalam air. Mampu menyaring besi namun dalam jumlah tidak banyak.

- Part 6

Dibagian ke -6 ini terdapat pasir aktif yang berfungsi untuk menghilangkan kandungan besi tingkat rendah $(\mathrm{Fe})$, maksudnya kandungan besi di dalam air tidak terlalu tinggi sehingga cukup dihilangkan dengan pasir aktif saja. Selain itu dapat menghilangkan bau besi yang di dalam air, menghilangkan sedikit Mangan (Mn2+).

4) Bak Air Bersih

Bak air bersih adalah bak penampungan air dari proses penyaringan multimedia filter yang nantinya akan digunakan kembali dan mengalir di mesin faset. Kegiatan ini akan bergulir jika proses faset terus berlangsung. Proses pengolahan limbah cair di industri lensa kacamata disajikan pada Gambar 2

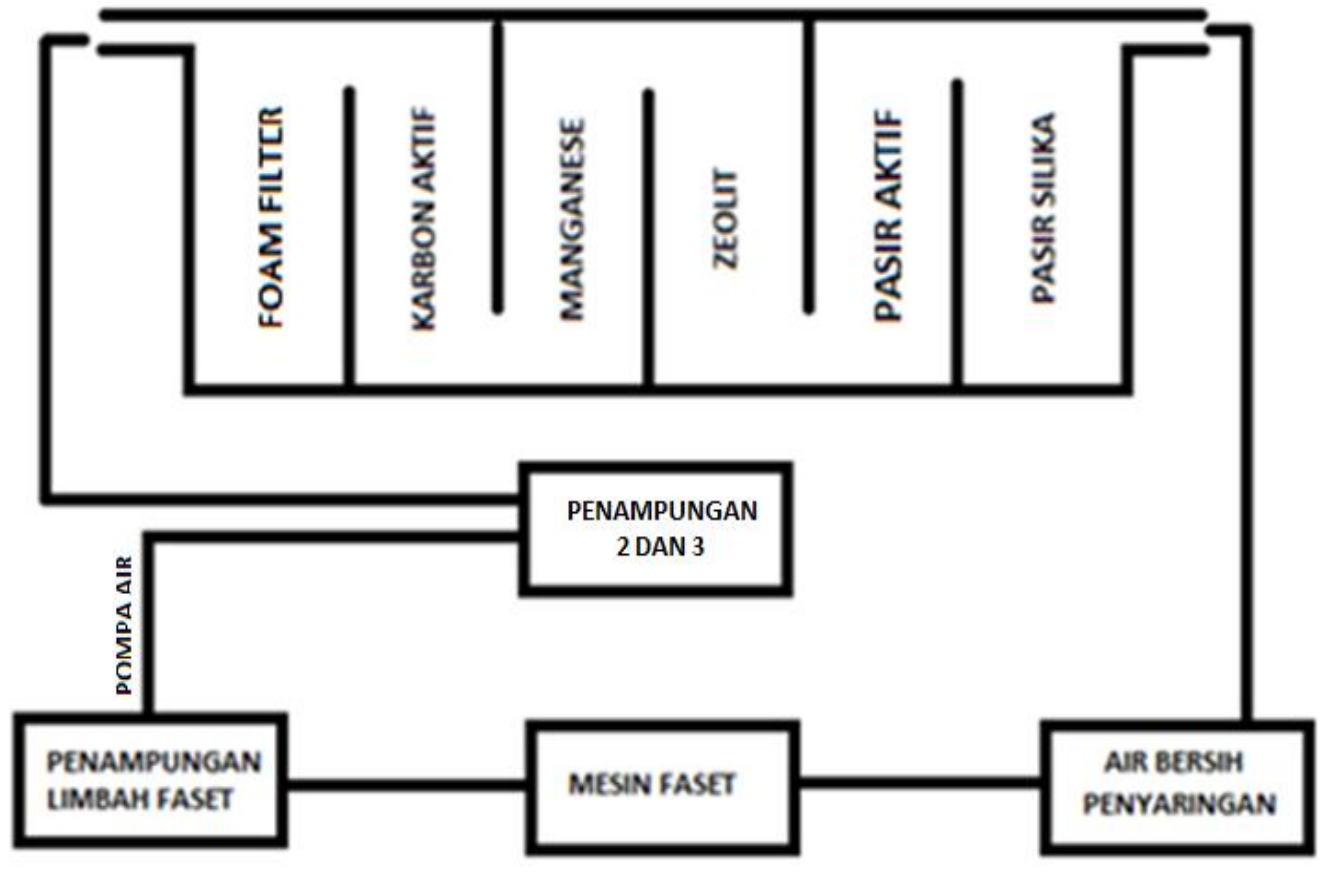

Gambar 2 Sketsa Multimedia Filter Pengolahan Limbah Cair Dispensing Pada Proses Faset. 


\section{HASIL DAN PEMBAHASAN}

\section{A. HASIL}

Tabel 1 Data Hasil Percobaan

\begin{tabular}{|c|c|c|c|c|c|c|}
\hline \multicolumn{7}{|c|}{ LEMBAR PERCOBAAN } \\
\hline & \multicolumn{2}{|c|}{ PERCOBAAN KE 1} & \multicolumn{2}{|c|}{ PERCOBAAN KE 2} & \multicolumn{2}{|c|}{ PERCOBAAN KE 3} \\
\hline OBSER VASI & $\mathrm{pH}$ & LAJUR AIR & $\mathrm{pH}$ & LAJUR AIR & $\mathrm{pH}$ & LAJUR AIR \\
\hline SAMPEL AIR & 7.1 & & 7.1 & & 7.1 & \\
\hline SAMPEL LIMBAH & $8.2-8.3$ & & $8.2-8.3$ & & $8.2-8.3$ & \\
\hline DEBIT AIR & $5 \mathrm{~L}$ & & $4.5 \mathrm{~L}$ & & $5 \mathrm{~L}$ & \\
\hline KOAGULASI & - & & - & & $0.02 \mathrm{mg}$ & \\
\hline PART 6 & 8.2 & Lancar & 7.9- 7.8 & Lancar & $7.6-7.7$ & Lancar \\
\hline PART 5 & 8.2 & Lancar & 7.7 & Lancar & $7.6-7.7$ & Lancar \\
\hline PART 4 & 8.2 & Lancar & 7.7 & Lancar & 7.6 & Lancar \\
\hline PART 3 & 8.2 & Lancar & 7.7 & Lancar & 7.6 & Lancar \\
\hline PART 2 & 8.1 & Lancar & 7.7 & Lancar & 7.5 & Lancar \\
\hline PART 1 & 8.1 & Lancar & 7.7 & Lancar & $7.1-7.0$ & Lancar \\
\hline BAKU MUTU AIR & 8.1 & $\mathrm{pH}>$ basa & 7.7 & $\mathrm{pH}>$ basa & $7.1-7.0$ & $\mathrm{pH}=$ basa \\
\hline
\end{tabular}

Pada percobaan ke 1 peneliti menggunakan limbah dari penampungan ke 1 dan langsung di alirkan ke multimedia filter. Pengamatan pada percobaan ke 1 adalah masih adanya partikel koloid halus berupa serpihan halus dari kikisan lensa dan kikisan dari batu mesin faset yang bercampur dan berterbangan yang mengakibatkan air limbah berwarna putih keruh. Dan setelah dilakukan penyaringan melalui Multimedia Filter polutan halus dari kikisan lensa dan kikisan batu mesin faset limbah cair tidak tersaring oleh multimedia filter karena banyanyaknya debit polutan. Sehingga dianggap tidak ada perubahan kadar $\mathrm{pH}$ pada treatment yang dilakukan, dan baku mutu air pun belum sesuai dengan harapan peneliti, karena limbah cair dispensing tidak dapat digunakan kembali untuk proses faset karena dapat menyebabkan penyumbatan pada mesin faset dan tidak dapat dibuang langsung ke perairan.

setelah melakukan percobaan ke 2 peneliti melakukan proses sedimentasi secara alami di bak penampungan ke 2 selama 24 jam. Kelebihan dari proses sedimentasi adalah limbah cair dispensing yang memiliki partikel koloid halus hasil dari kikisan lensa dan batu mesin faset terjadi pengendapan, sehingga air limbah terlihat tidak terlalu putih keruh. Pada percobaan ke 2 limbah cair lebih baik dibandingkan percobaan ke 1, karena memiliki $\mathrm{pH}$ air yang menurun sebesar $92.77 \%$. serta partikel koloid berupa kikisan lensa dan kikisan batu mesin faset yang terdapat pada percobaan pertama sudah tidak terlihat mengapung dan berada di dasar bak penampungan dan hasil output air limbah setelah melalui multimedia filter pun sudah terlihat jernih dibandingkan sebelumnya. 
Percobaan ke 2, output limbah cair dispensing setelah diberikan treatment adalah $\mathrm{pH}$ 7,7. Dengan demikian limbah cair sudah dapat dialirkan ke perairan, namun belum maksimal untuk digunakan kembali. Berikut dokumentasi hasil $\mathrm{pH}$ part 1 sampai part 6 di percobaan ke 2 :

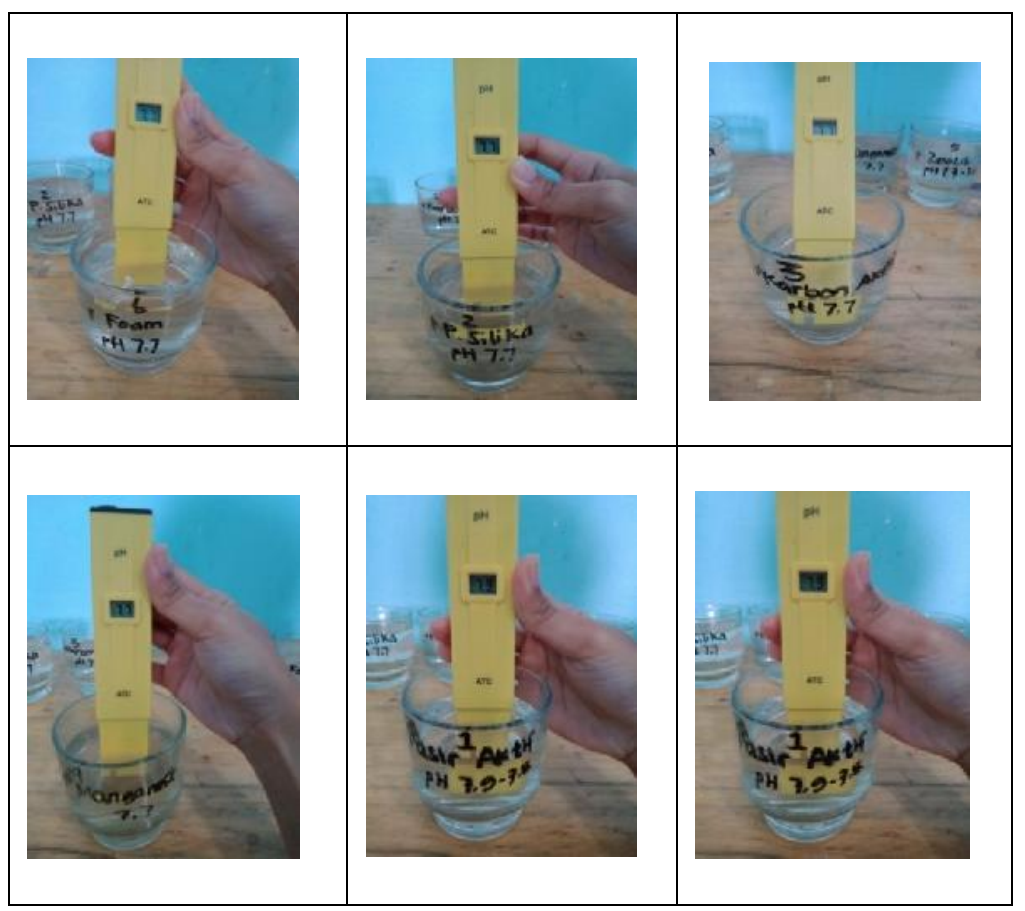

Gambar 3 Tahapan pH di percobaan ke 2

Percobaan ke 3 peneliti menambahkan kandungan kimia koagulan dengan jenis PAC (Poly Alumunium Chloride), PAC yang digunakan adalah sebesar $0.02 \mathrm{mg}$ dengan debit air kurang lebih $1500 \mathrm{ml}$. Pemberian PAC diawasi oleh tenaga ahli. Penggunaan PAC dapat mengikat partikel koloid halus berupa hasil kikisan dari lensa dan batu mesin faset menjadi flok-flok halus yang akan mengendap pada dasar bak penampungan. Pada pengamatan percobaan ke 3 setelah melalui multimedia filter hasil $\mathrm{pH}$ output dari limbah cair dispensing menurun sebesar $84.52 \%$, yaitu $\mathrm{pH} 7.1$ - 7.0 dan air limbah sudah tidak terlihat polutan serta lebih jernih. Dan dapat memenuhi kriteria baku mutu air, yaitu memiliki keseimbangan kandungan asam dan basa, sehingga tidak merusak ekosistem saat dibuang ke perairan dan dapat digunakan kembali untuk kegiatan faset. Berikut hasil output air limbah setelah melalui multimedia filter :

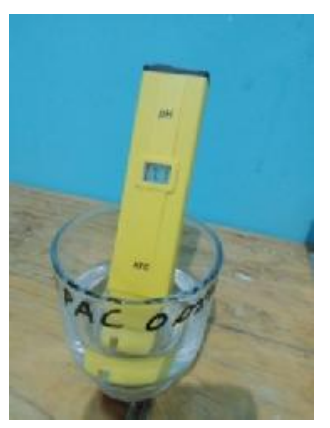




\section{Gambar 4 Output pH di Percobaan ke 3}

\section{B. PEMBAHASAN}

\section{Air Limbah}

Pada percobaan ke 1, air limbah cair dispensing terdapat polutan yang bersifat basa dengan $\mathrm{pH} 8.3$ - 8.4, ketika dilakukan penyaringan menggunakan multimedia filter tidak banyak berpengaruh terhadap $\mathrm{pH}$ dikarenakan kandungan basa dan banyaknya polutan yang terkandung dalam air limbah tidak sebanding dengan kapasitas media pada multimedia filter, sehingga hasil output dari multimedia filter hanya mendapatkan baku mutu air sebesar $\mathrm{pH}$ 8.1.

Lalu dilakukan percobaan ke 2, dengan melakukan sedimentasi alami terhadap limbah cair dispensing selama 24 jam. Sedimentasi alami ini dilakukan agar kandungan polutan yang terdapat pada limbah cair dispensing mengendap di dasar bak penampungan ke 2 . Dengan adanya tindakan sedimentasi ini maka peneliti harus memisahkan air limbah yang sudah terpisah dengan polutan ke bak penampungan ke 3 . Namun walaupun kegiatan sedimentasi ini dilakukan selama 24 jam, proses faset pada saat jam kerja dan pengolahan air limbah tidak terhenti, berikut mekanismenya :

- Pada bak penampungan ke 1 terdapat air limbah baru yang dialirkan langsung dari mesin faset, sehingga tidak mengganggu terjadinya proses sedimentasi di bak penampungan ke 2 .
- Setelah pelayanan kesehatan di Optik Ahur tutup, kegiatan pemindahan air limbah dari penampungan ke 1 ke penampungan ke 2 baru akan dilakukan menggunakan pompa air, kegiatan ini dilakukan agar air limbah aktif di penampungan ke 1 tidak tercampur dengan air limbah di bak penampungan ke 2 yang sedang di sedimentasi secara alami selama 24 jam.

- Setelah sedimentasi alami selama 24 jam, air limbah di penampungan ke 2 telah terpisah dengan polutan yang ada di dalamnya. Lalu air yang telah terpisah dengan polutan tersebut di alirkan ke bak penampungan ke 3 menggunakan pompa air untuk selanjutnya dialirkan ke multimedia filter untuk di filtrasi. Dan hasil output air limbah dispensing setelah melalui multimedia filter menghasilkan baku mutu air limbah sebesasar $\mathrm{pH}$ 7.7. nilai tersebut sebenarnya telah memenuhi standar baku mutu air limbah menurut Peraturan Menteri Lingkungan Hidup Republik Indonesia Nomor 5 Tahun 2014 Tentang Baku Mutu Air Limbah.

Maka dengan adanya pH 7.7 pada percobaan ke 2 dirasa belum memenuhi kriteria penggunaan air bersih, maka peneliti melakukan percobaan ke 3, yaitu menambahkan kandungan kimia, yaitu PAC (Poly Alumunium Chloride) sebanyak $0.02 \mathrm{mg}$ (sangat sedikit) untuk membantu menetralisasi kandungan basa yang terdapat pada limbah cair dispensing di Optik Ahur. Kegiatan penambahan PAC tersebut 
dilakukan di bak penampungan ke 3 sebelum masuk ke multimedia filter. Dan setelah mencampurkan PAC ke dalam air limbah cair dispensing, maka air limbah di alirkan ke dalam multimedia filter untuk di filtrasi agar kandungan kimia berupa asam dan basa serta polutan berupa kikisan lensa dan kikisan batu mesin faset yang terdapat pada limbah cair dispensing memiliki $\mathrm{pH}$ seimbang dan dapat diginakan kembali untuk kegiatan faset oleh tenaga kesehatan Opthometris. Setelah penambahan PAC di penampungan ke 3 polutan yang masih tersisa dari hasil perpindahan air limbah dari penampungan ke 2 berubah menjadi flok-flok yang memiliki tekstur seperti lumpur, lalu ketika melewati multimedia filter air penampungan ke 3 ini tidak terlihat meninggalkan koloid yang berupa kikisan lensa dan kikisan batu mesin faset.

Dengan adanya multimedia filter ini diharapkan dapat memanfaatkan air limbah cair dispensing untuk dapat digunakan kembali dalam proses faset oleh Optometris sebagai tenaga kesehatan dilingkungan optik, sudah sepatutnya memahami sanitasi lingkungan di optiknya dan personal hygiene sebaik-baiknya, maka hasil proses faset ini sudah seharusnya menjadi perhatian oleh pemilik optik dan tenaga Opthometris yang berada di dalamnya. Pengolahan limbah cair dispensing diharapkan sesuai dengan baku mutu air limbah sehingga dapat digunakan kembali dan dapat di alirkan keperairan.

\section{Mekanisme Multimedia Filter}

Mekanisme kerja Multimedia Filter adalah dengan menggunakan siatem penyaringan dengan cara lambat dengan sistem overflow agar tidak terjadinya peluapan pada bak penampungan dan pada Multimedia Filter itu sendiri, karena jika terjadi peluapan pada part yang terdapat di Multimedia filter, maka akan terangkat oleh debit air dan air limbah yang berada pada penampungan 1,2,3 tidak dapat di proses dengan baik. Penyaringan lambat, yaitu penyaringan dengan memanfaatkan energi potensial air itu sendiri sehingga hanya melalui gaya gravitasi.

\section{Hasil Penambahan Indikator}

Limbah cair dispensing pada saat awal produksi memiliki tingkat kekeruhan yang pekat dan kadar $\mathrm{pH}$ tinggi yang bersifat basa. Setelah melalui tiga kali percobaan penelitian maka didapatkan hasil bahwa pengolah limbah cair ini adalah melalui 3 bak penampungan dan di penampungan ke 3 di tambahi dengan PAC. Lalu dialirkan ke Multimedia Filter sehingga mendapatkan hasil output yang jernih dan dapat digunakan kembali oleh tenaga Opthometrist untuk proses faset.

\section{KESIMPULAN}

Berdasarkan seluruh tahapan yang telah dilakukan pada Karya Tulis Ilmiah yang berjudul "Pengolahan Limbah Cair Dispensing Pada Proses Faset Dengan Menggunakan 
Multimedia Filter di Optik Ahur Kota Cimahi

Tahun 2020" telah di peroleh kesimpulan, yaitu :

1. Dengan adanya multimedia filter peneliti dapat mengetahui bagaimana cara pengolahan limbah cair dispensing pada proses faset menggunakan multimedia filter. Multimedia filter dapat menurunkan pH limbah cair dispensing di Optik Ahur dari $\mathrm{pH} 8.3$ menjadi pH 7.7 atau sebesar 92.77\% di percobaan ke 2, dan dari $\mathrm{pH} 8.3$ - 8.4 menjadi pH 7.1 - 7.0 atau sebesar $84.52 \%$ di percobaan ke 3, yaitu dengan karakteristik air limbah yang tidak berbau dan tidak berwarna. Sehigga percobaan ke 2 telah memenuhi standar baku mutu air limbah. Dan output limbah cair dispensing sudah dapat dialirkan atau dibuang ke perairan dan dapat digunakan kembali untuk kegiatan faset oleh tenaga kesehatan Opthometris.

2. Dengan adanya penelitian ini, peneliti dapat mengetahui bahwa Optik Ahur belum melakukan pengolahan air limbah faset secara mandiri. Dan dengan adanya penelitian ini, peneliti dapat memberikan solusi atas permasalahan tentang limbah cair dispensing pada proses faset.

\section{DAFTAR PUSTAKA}

A Marcelia, 2020. Limbah B3.[serial online] 2015 [dikutip 11 mei 2020];1(1):[3 halaman]. Tersedia dari :URL http://www.Academia.edu.

Andi Tri Sahputra, 2015. Limbah Dengan Netralisasi. [serial online] 2015 [dikutip 28
Januari 2020];2-3:[20 halaman]. Tersedia dari :URL http://www.Academia.edu.

Arifudin dan Setiyono, 2018. Pengolahan Limbah Cair Industri Lensa Kacamata Kapasitas 1,5 $\mathrm{m}^{3} /$ hari. Pusat Teknologi Lingkungan Kedeputian Teknologi Sumber Daya Alam Badan Pengajian Penerapan Teknologi.

Mentri Tenaga Kerja Dan Transmigrasi Republik Indonesia, 2008. Penetapan Standar Kompetensi Kerja Nasional Indonesia Sektor Industri Instrument Optik sub Sektor Industri Kacamata Bidang Refraksi Optisi Sub Bidang Optisi.

Okky Marben, 2019. Limbah B3. [serial online] 2019 [dikutip 30 Januari 2020];1-8:[27 halaman]. Tersedia dari :URL http://www.Academia.edu.

Peraturan Menteri Lingkungan Hidup Republik Indonesia No. 5 Tahun 2014. Baku Mutu Air Limbah

Peraturan Pemerintah No. 101 tahun 2014. Pengolahan (Limbah B3).

Peraturan Pemerintah No. 82 Tahun 2001. Pengolahan Kualitas Air Dan Pencemaran Air.

Punmia BC, 1979. Water Supply Engineering. Environmental Engineering Vol. I, Standard House, Delhi, India.

Prof. Sugiono, 2016. Metode Penelitian Kombinasi (Mixed Methods). Edisi ke 8. PT. Alfabeta. Bandung

Musdalifah Yusuf, 2015. Metode Penelitian Eksperimen.[serial online] 2015 [dikutip 14 februari 2020];5(1):[19 halaman]. Tersedia dari :URL http://www.Academia.edu

Widea Ernawati, 2015. Pengaruh Penggunaan Gadget Terhadap Penurunan Tajam Penglihatan Pada Anak Usia Sekolah (6-12 Tahun) Di Sd Muhammadiyah 2 Pontianak Selatan. [serial online] 2015 [dikutip 06 
april 2020];4(1):[7 halaman]. Tersedia dari : URL http;//drive.google.com/file/d/0Bx8eC1Qkv spuRkd2W1Fytm5ydkk/view

Dini Silvi Purnia dan Ai Ilah Warnilah, 2017. Implementasi Data Mining Pada Penjualan Kacamata Menggunakan Algoritma Apriori. [serial online] 2017 [dikutip 06 april 2020];1(1):[9 halaman]. Tersedia dari : $\quad$ URL https://repository.bsi.ac.id/index.php/unduh litem/1926/2776-7144-1-SM.pdf

Wawan Setiawan, 2017. Era Digital dan Tantangannya. [serial online] 2017 [dikutip 06 april 2020]1(1,2):[9 halaman]. Tersedia dari : URL eprints.ummi.ac.id/151/2/1. Era Digital dan Tantangannya.pdf 